\title{
Routing Strategies for Emergency Management Decision Support Systems During Evacuation
}

\author{
JOSEPH YU, ${ }^{1, *}$ ANURAG PANDE, ${ }^{1}$ N. NEZAMUDDIN,,${ }^{1, * *}$ \\ VINAYAK DIXIT, ${ }^{3}$ AND FRANCES EDWARDS ${ }^{4}$ \\ ${ }^{1}$ Department of Civil \& Environmental Engineering, California Polytechnic State \\ University, San Luis Obispo, California, USA \\ ${ }^{2}$ Center for Transportation Research, University of Texas-Austin, Austin, Texas, \\ USA \\ ${ }^{3}$ School of Civil and Environmental Engineering, The University of New South \\ Wales, Sydney, Australia \\ ${ }^{4}$ Department of Political Science, San Jose State University, San Jose, \\ California, USA
}

\begin{abstract}
Simulation studies of urban transportation networks have been increasingly applied to evacuation planning. The level of detail provided within a traffic simulation model allows for devising strategies for evacuation and emergency response. In this research, simulation model of downtown San Jose, California, transportation network is developed to evaluate the efficiency of the evacuation process under hypothetical scenarios. Although the scenarios evaluated herein are not exhaustive, they demonstrate the potential of the simulation approach for managing traffic engineering aspects of the emergency response. The scenarios described here include the use of contraflow lanes, traffic incidents on the network, and a modal shift to transit by evacuees. It was found that among the tested scenarios, reduction in number of vehicles on the road through increased public transit ridership in conjunction with rerouting vehicles and contraflow operations on key corridors would be the most efficient approach. The major contribution of this study is the ability to examine not only the travel times for evacuees but also mobility and accessibility for emergency vehicles. The time to access location(s) under distress, while ensuring efficient evacuation operations at the same time, is critical to reducing losses during an unfolding human-caused disaster.
\end{abstract}

Keywords no-notice disasters, emergency traffic operations, traffic simulation, evacuation

*Current affiliation: GTS Inc., Walnut Creek, California, USA.

${ }^{* *}$ Current affiliation: Department of Civil Engineering, Valparaiso University, Indiana, USA.

Address correspondence to Anurag Pande, Department of Civil \& Environmental Engineering, California Polytechnic State University, 1 Grand Avenue, San Luis Obispo, CA 93407, USA. E-mail:apande@calpoly.edu 


\section{Introduction}

The terrorist attacks on September 11 as well as more recent coordinated attacks on transit centers in Mumbai, Madrid, and London have underscored the importance of evacuation planning. Computational advancements have now made it possible to simulate urban transportation networks with greater detail and accuracy. This research study aimed to develop a framework for creating effective evacuation plans following a human-caused disaster in downtown San Jose, California, accounting for the peak hour traffic. Specifically, this research evaluates contraflow, rerouting strategies, and the potential effect of promoting transit usage during evacuation on evacuating traffic and emergency vehicle entry. Note that these specific evaluations serve as examples of traffic strategies that can be evaluated by the proposed approach. In addition to evaluating evacuation metrics, the research also examines the times for emergency personnel to reach the affected locations from various dispatch locations. These dispatch locations were identified based on the knowledge of the local emergency response procedures.

The first task for this research was to develop a network model in VISSIM, which required data for network geometry drawn from Google Maps images, signal timings provided by the City of San Jose, and turning movement counts from various sources detailed later. At select intersections, turning movement counts were used to validate the network with Geoffrey E. Havers (GEH) statistic, which are calculated to assess the difference between observed and simulated counts. For freeways the simulation model was validated using field travel time data. Once the base network was validated, various scenarios were tested to estimate evacuation and emergency response vehicle arrival times.

The article begins by presenting the literature review of related past works, followed by a description of the network's modeling procedure, an analysis of various evacuation scenarios, and conclusions. In the Conclusions section, details on future research ideas and more examples of potential applications are also provided.

\section{Background: Simulation Applications}

Traffic simulation packages that are currently available offer a wide range of practical traffic analysis tools such as evaluation of alternative roadway treatments, safety analyses, and evacuation studies. Traffic modeling tools can be characterized into three classes: microscopic, mesoscopic, and macroscopic (Boxill \& Yu, 2000). Microscopic models simulate individual vehicle movements at small time intervals whereas models that aggregate traffic flow are termed as "macroscopic." Mesoscopic models have microscopic and macroscopic characteristics. Groups of vehicles or platoons are simulated and microscopic model results are aggregated for use in these models (Naghawi \& Wolshon, 2010).

Macroscopic models are more appropriate for regional or large-scale studies. They are typically used by transportation planners or demand modelers. Planners take a systematic process to translate land-use, household, and employment characteristics, and transportation supply into predictions of current and future travel patterns and demand, through mathematical formulation and simplification. Instead of modeling individual vehicles, cars are aggregated and measurements of flow, density, and average speed are then measured. These models are less accurate than their microscopic simulation counterparts but are faster and require fewer variables for network coding. Networks that are developed in this way also provide a static view of the transportation system appropriate for long-term planning (Molaghasemi \& Abdel-Aty, 2003; Rousseau et al., 2007). In the past, traffic simulation 
has been used to analyze emergency evacuation conditions for vulnerable coastal areas in the southeastern United States. When Hurricane Floyd struck in 1999, evacuations of North and South Carolina resulted in highly congested arterial highways, and as a result, several states created Lane Reversal Plans (or contraflow lanes) for interstates and/or divided highways along evacuation routes. To test the plans' effectiveness a major research study was funded by the North Carolina Department of Transportation (NCDOT) to use simulation modeling to determine performance measures. The study concluded that lane reversals provided considerable capacity increases to traffic attempting to exit the disaster area via Interstate 40 in North Carolina (Tagliaferri, 2005).

In another research study by Theodoulou (2003), CORSIM 5.0 simulation model results were used to evaluate the effectiveness of a contraflow segment on westbound I-10 out of New Orleans. Results showed that the use of contraflow lanes could increase the traffic flow significantly and alternative plans that were developed were also able to display effective roadway usage. Similar conclusions were made by Dixit et al. (2008) in the evacuation study of Tampa using Interstate 4; they found that location of contraflow crossover points were critical for efficient evacuation operations.

More relevant to this research is the evacuation preparedness that includes urban areas affected by human-caused disaster. Two such studies have been conducted by applying microscopic traffic simulation for assessing effective, postdisaster routing of emergency vehicles specifically for human-caused disasters. Elmitiny et al. (2007) simulated different strategies to evacuate a transit station to help the LYNX bus service in the Orlando Metropolitan region evaluate its evacuation plans. Also, Mollaghasemi and Abdel-Aty (2003) analyzed the highway network around Orlando International Airport to identify the most effective routing strategies for emergency vehicles.

Other study conducted by Haghani et al. (2003) provided an integer programming model to conduct a simulation experiment in routing Emergency Medical Service (EMS) using a dynamic shortest path algorithm. Through a series of mathematical tests to verify the model's validity and sensitivity to changes in various parameters, the authors determined that the new model developed in this study provided advantages in real-time emergency vehicle dispatching. Through a dynamic network, individual nodes were treated as moving vehicles that provided a comprehensive, twofold tool. First of all, the emergency response capability was improved, and secondly, dynamic travel time helped provide an optimal emergency response time to severe incidents.

Pal et al. (2002) used ArcView Geographic Information Systems (GIS) and traffic simulation software Oak Ridge Evacuation Model System (OREMS) 2.5 to develop evacuation models for two counties along the Alabama Gulf Coast. This southeastern coast of the United States is particularly vulnerable to hurricanes. Arcview GIS was used to organize various input data ranging from roadway links to population data in preparation for entry into OREMS. The resulting simulation showed that a complete evacuation of Baldwin and Mobile Counties would take approximately $21 \mathrm{~h}$ and $8 \mathrm{~h}$, respectively.

The aforementioned studies, though thorough and helpful in their own way, lack the effective integration of the routing strategies (for evacuees as well as for the emergency vehicles) within the overall emergency response framework for the community. In addition, the regional traffic model developed by Sisiopiku et al. (2004) is limited in its ability for real-time simulation of emergencies and does not model vehicular behavior at the microscopic level. Our research is an attempt to enhance the knowledge in this area with an effective integration strategy that includes not just the evacuation component, but also travel times for emergency vehicles such as fire trucks. It is worth mentioning that this study focuses on addressing traffic related aspects of emergency response. Comprehensive 


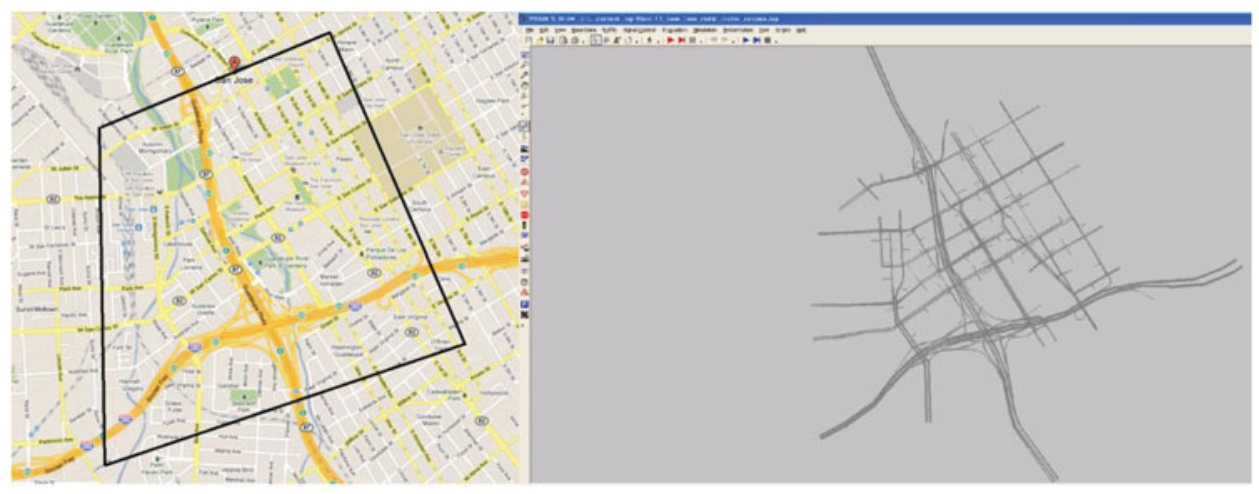

Figure 1. Evacuation study boundary. Left: Google Maps; Right: VISSIM model.

response to a human-caused disaster involves much more than just traffic analysis including but not limited to law enforcement response and the number of fatalities and injuries. This analysis focuses on the traffic behavior with dispatching emergency responders to the sites of attack and evacuating people out of the area being the primary objectives. The information presented herein can be used by decision makers to learn about the potential of microscopic traffic simulation to help assess various scenarios. Although microscopic models require extensive amount of data and computing resources, they provide more realistic representation of traffic operations as well as detailed outputs such as estimated travel speed, delay, and travel times that are very useful measures of effectiveness for evaluating traffic performance during emergency response (Naghawi \& Wolshon, 2010).

\section{Network Modeling}

The evacuation plans were tested on the network during the PM peak hour on a weekday. Afternoon peak period was selected because it represented the worst-case scenario of background traffic for a disaster involving multiple threats throughout the downtown area that would add to the already congested freeway and highway networks. The network modeling procedure, including the details of data collection, network modeling, and validation are described in this section. Further details of these procedures can also be found in Pande et al. (2012). The evacuation study boundary is displayed in Figure 1. Note that VISSIM was the tool of choice for simulation the network based on the authors' expertise and familiarity with the tool. There are other similarly capable microscopic simulation tools that could be used for similar analysis (e.g., PARAMICS, CORSIM, etc.).

\subsection{Data Collection}

To calibrate the simulation model for the base case (No disaster) PM peak period, volume data for downtown surface streets were obtained from the City of San Jose. In addition, freeway volume count data for I-280 and Highway 87 were obtained from the Caltrans Performance Measurement System (PeMS). Lastly, a regional Cube Voyager model from the City of San Jose provided another means of obtaining approximate, directional traffic volumes throughout the entire network. After the traffic data was obtained a calibration base model was established. The next step involved the virtual construction of a traffic model that would accurately simulate driving conditions encountered during the base case. 


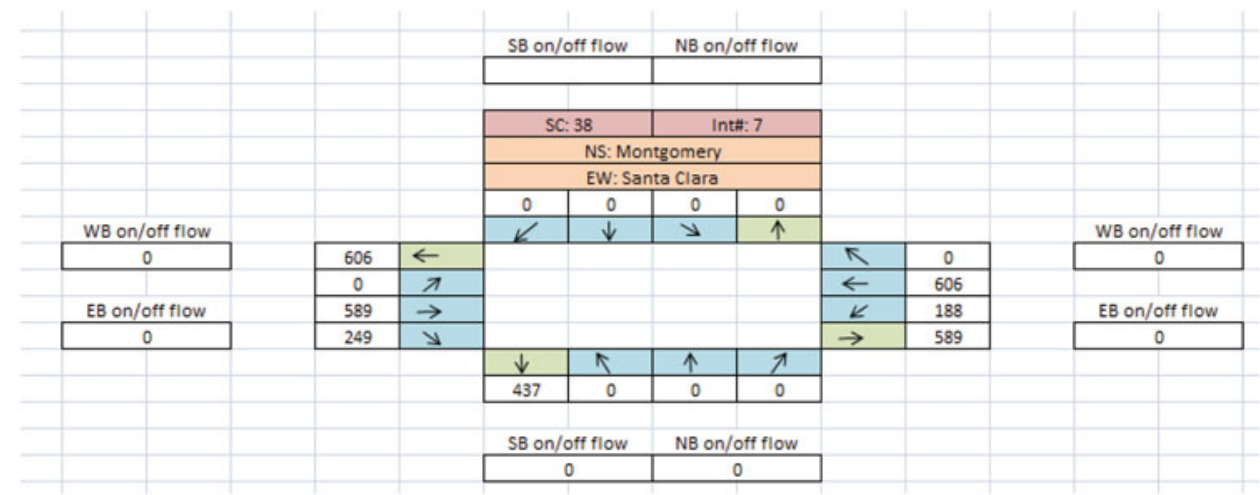

Figure 2. Traffic volume excel spreadsheet.

The network creation included the links or roads necessary to travel upon, traffic signals, stop signs, yield control, reduced speed areas, and desired speed decisions.

Once these steps were complete, the different driving behavior parameters that VISSIM offers could be implemented to calibrate the simulation to match reality as closely as possible. The final network consisted of 974 links, 45 signalized intersections, and 79 vehicle inputs. During the peak hour, signals were modeled as Ring Barrier Controller in VISSIM because it represented the signal timing pattern provided by the City. For more details on the signalized intersection modeling one may refer to Pande et al. (2012).

The final step to creating a fully functional network in VISSIM involved compiling available surface street volume data into one spreadsheet. The best available data was from the City of San Jose which was sent in a Microsoft Excel file that included intersection counts throughout downtown San Jose from 2006 to 2009. However, this information itself was insufficient in determining all the volumes at every intersection. The next, most favorable option was to refer to the Cube Voyager data, also provided by the City of San Jose, which included directional traffic volumes throughout the network. Prior to coding the counts in VISSIM, all traffic count data from the City of San Jose's Microsoft Excel file were entered into one spreadsheet. An intersection was shown as four different approaches (see Figure 2 for an example).

The purpose of the directional "on/off flow" cells shown in Figure 2 was to calculate the volume difference between the upstream intersection departure and downstream intersection approach. Although the spreadsheet in Figure 2 shows a completely balanced intersection, prior to the volume balancing, if the "on/off flow" cells presented a negative volume, a volume had to exit the road before the next intersection. However, if the cell value was positive, that signified the number of vehicles indicated in the cell should enter the road prior to the adjacent intersection. These were modeled as midblock entrances/exits.

\subsection{VISSIM Network Calibration and Validation}

Calibration of the completed VISSIM network for the base case PM peak scenario involved refining and adjusting the network to simulate realistic driving conditions. Calibration of the microscopic simulation model included adjusting the car-following model parameters and traffic speeds. The VISSIM model was calibrated by varying the microscopic behavioral 
parameters in VISSIM to ensure the model's volumes represented those observed in the City of San Jose or Caltrans' data.

The calibration of the network was assessed using the Geoffrey E. Havers (GEH) statistic. The simulation was run ten times for a period of 4500 seconds using different random seed numbers. The field counts by the City of San Jose were compared to the simulation turning volumes that were collected at the end of the simulation period.

GEH statistics are commonly used in transportation analysis and simulation to compare two sets of traffic volumes. The empirical formula is similar to that of a chi-squared test shown below in the following equation:

$$
G E H=\sqrt{\frac{2(M-C)^{2}}{M+C}}
$$

where,

$\mathrm{M}=$ traffic count from the simulation model

$\mathrm{C}=$ traffic count volume observed in the real world.

The Federal Highway Administration's guideline for calibrating simulation models states that the value of the GEH statistic should be less than five for at least $85 \%$ of the volume check points (Federal Highway Administration [FHWA], 2012). The simulation of downtown San Jose was assumed to be reasonably accurate when GEH statistics for all 36 turning movements were fewer than five as shown in Table 1. None of the recorded volumes displayed a GEH statistic over five which affirmed that the simulation network was calibrated for the surface streets.

In addition to the GEH statistic, the validation of the freeway section involved comparing the field travel times that were recorded on the sections included in the study area (I-280 NB and SB and Highway 87 NB and SB), with those observed in the simulation for the same freeway sections.

According to calibration targets developed by Wisconsin Department of Transportation (DOT) for their Milwaukee freeway system model, for model travel times to be accepted, they must be within $15 \%$ of the observed travel times for more than $85 \%$ of the cases (Dowling et al., 2004). The difference in travel times between observed and simulated were much below the recommended $15 \%$ target.

\section{Alternative Scenarios}

All the disaster scenarios involved a series of events that occurred around downtown San Jose on a Friday afternoon. To further exacerbate matters, the coordinated attacks occur in high-profile areas such as the HP Pavilion and San Jose Convention Center among other locations around downtown San Jose during the afternoon peak hour at 4:00 pm (Figure 3). The HP Pavilion was hosting a business seminar, with 19,100 attendees on site. All 1,800 onsite parking slots were occupied, and adjacent city and privately owned parking lots were full. Adjacent lots were located on Santa Clara Street at Delmas, Santa Clara Street at Cahill, and Autumn Street north of Julian. The Santa Clara at Delmas lot has exit potential onto Santa Clara both east and west bound, while the Santa Clara Street at Cahill exits onto Autumn and then Santa Clara in either direction, or Montgomery southbound, with the first cross street being Park Avenue. Please refer to Figure 3 for a detailed street map of the study area. 
Table 1

Geoffrey E. Havers statistic calibration summary for the City of San Jose model

\begin{tabular}{|c|c|c|c|c|}
\hline \multirow[b]{2}{*}{ Roadway/Intersection } & \multirow{2}{*}{$\begin{array}{l}\text { Movement } \\
\text { Direction }\end{array}$} & \multicolumn{2}{|c|}{ Volume (vehicles) ${ }^{\mathrm{a}}$} & \multirow{2}{*}{$\begin{array}{c}\text { Geoffrey E. Havers } \\
\text { Statistic }\end{array}$} \\
\hline & & Simulation & Actual & \\
\hline \multirow{12}{*}{$\begin{array}{l}\text { Almaden and San } \\
\text { Carlos }\end{array}$} & $\mathrm{NbR}$ & 132 & 158 & 2.17 \\
\hline & $\mathrm{NbT}$ & 285 & 348 & 3.56 \\
\hline & $\mathrm{NbL}$ & 69 & 88 & 2.10 \\
\hline & EbR & 217 & 209 & 0.54 \\
\hline & $\mathrm{EbT}$ & 826 & 759 & 2.37 \\
\hline & $\mathrm{EbL}$ & 198 & 184 & 1.01 \\
\hline & $\mathrm{SbR}$ & 103 & 100 & 0.29 \\
\hline & $\mathrm{SbT}$ & 1009 & 1017 & 0.25 \\
\hline & $\mathrm{SbL}$ & 113 & 104 & 0.89 \\
\hline & $\mathrm{WbL}$ & 120 & 106 & 1.33 \\
\hline & WbT & 588 & 514 & 3.16 \\
\hline & $\mathrm{WbR}$ & 94 & 83 & 1.22 \\
\hline \multirow[t]{12}{*}{ Almaden and Park } & $\mathrm{NbR}$ & 34 & 36 & 0.37 \\
\hline & $\mathrm{NbT}$ & 223 & 237 & 0.93 \\
\hline & $\mathrm{NbL}$ & 35 & 37 & 0.36 \\
\hline & EbR & 116 & 117 & 0.13 \\
\hline & $\mathrm{EbT}$ & 83 & 86 & 0.37 \\
\hline & $\mathrm{EbL}$ & 97 & 105 & 0.79 \\
\hline & $\mathrm{SbR}$ & 87 & 86 & 0.10 \\
\hline & $\mathrm{SbT}$ & 955 & 965 & 0.33 \\
\hline & $\mathrm{SbL}$ & 43 & 48 & 0.70 \\
\hline & $\mathrm{WbL}$ & 178 & 163 & 1.17 \\
\hline & WbT & 112 & 104 & 0.79 \\
\hline & WbR & 68 & 60 & 0.98 \\
\hline \multirow{12}{*}{$\begin{array}{l}\text { Market and Santa } \\
\text { Clara }\end{array}$} & $\mathrm{NbR}$ & 47 & 41 & 0.93 \\
\hline & $\mathrm{NbT}$ & 276 & 231 & 2.85 \\
\hline & $\mathrm{NbL}$ & 79 & 69 & 1.14 \\
\hline & EbR & 119 & 114 & 0.49 \\
\hline & $\mathrm{EbT}$ & 613 & 581 & 1.29 \\
\hline & $\mathrm{EbL}$ & 92 & 87 & 0.51 \\
\hline & SbR & 125 & 80 & 4.48 \\
\hline & $\mathrm{SbT}$ & 886 & 760 & 4.40 \\
\hline & $\mathrm{SbL}$ & 79 & 118 & 3.93 \\
\hline & WbL & 107 & 90 & 1.68 \\
\hline & WbT & 448 & 395 & 2.56 \\
\hline & WbR & 91 & 80 & 1.20 \\
\hline
\end{tabular}

$\mathrm{Nb}, \mathrm{Eb}, \mathrm{Sb}, \mathrm{Wb}$ for North-, East-, South-, West-bound, respectively; $\mathrm{L}=$ left; $\mathrm{R}=$ right; $\mathrm{T}=$ through.

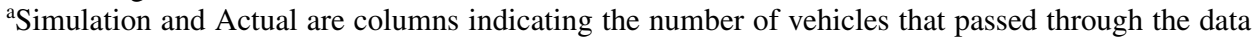
collection point during simulation. 


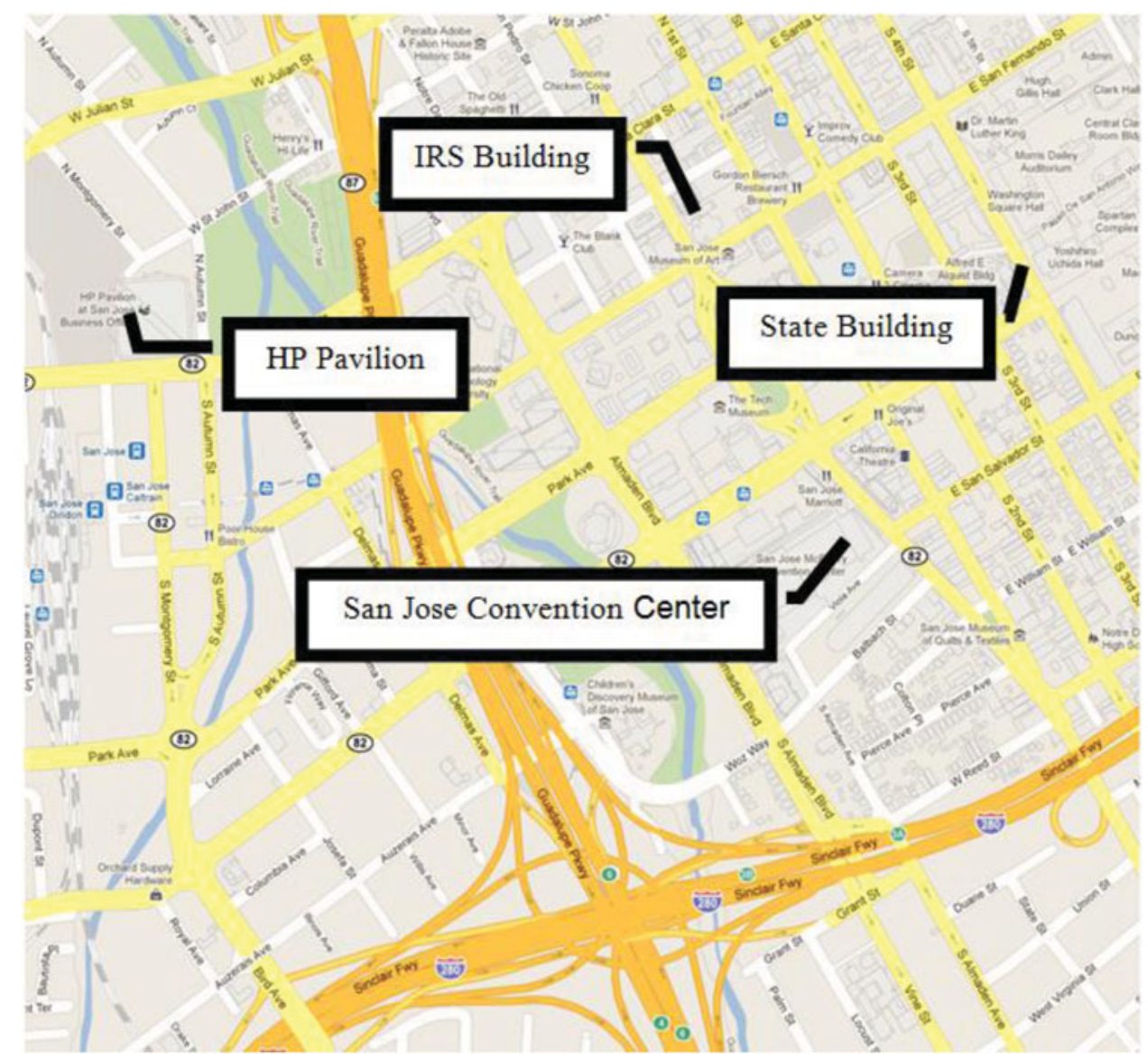

Figure 3. Location of sites attacked.

The simulation of disaster traffic modeling assumed near simultaneous terrorist attacks at four downtown San Jose locations: HP Pavilion on Santa Clara Street, IRS building on Market Street, Convention Center on Almaden Boulevard, and State of California Building on 100 Paseo de San Antonio. Three hospitals and fire stations were identified as locations for the emergency responders. The primary hospitals to receive patients from the disaster were (1) O' Connor Hospital, (2) Valley Medical Center, and (3) Regional Medical Center. These were destinations for ambulances from the four disaster sites. The three fire stations in the study were the origins for the emergency responders, with the four terrorist targets being the destinations. The attacked sites were also the origins for the evacuees (general public), with their destinations being different exit points on the network. Note that the city authorities will have the ability to examine different disaster scenarios (possibly including different attack sites, etc.) using the same base traffic simulation model developed here with marginal effort.

Given the above disaster scenario, various response strategies were tested in the simulation model to observe that yielded the most efficient way to evacuate and have the emergency response reach the hospitals from the disaster areas. All disaster scenarios, as well as the base scenarios in VISSIM, included a 5-min simulation warm-up period, 
followed by a 60 -minute simulation time, and a 5-minute "clearing period" for the remaining cars to reach their destinations. It should be noted that these scenarios are not necessarily the optimal ones but are used herein to exemplify the evaluations that can be carried out using the simulation model.

In addition, only emergency vehicles (such as ambulances and fire vehicles) traveling on I-280 NB or SB could enter or exit into the downtown area. These vehicles were defined as a separate vehicle class in VISSIM. For I- $280 \mathrm{NB}$, the closed off-ramps were from $4^{\text {th }} \mathrm{St}$. to Bird Avenue while on I-280 SB, the exits closed ranged from Bird Avenue to E. Virginia St. In addition, Highway 87 NB and SB were completely closed to all vehicular traffic except for emergency vehicles. The purpose behind this action was to prevent further gridlock on city streets, as well as potentially providing emergency vehicles a quicker, more efficient route to access the bombing locations. In addition, due to the large number of vehicles expected to exit out of the parking lot across from the San Jose Convention Center, a new intersection was added at Woz Way and Almaden Boulevard. Another intersection was coded into the network at San Pedro and Santa Clara Streets for the expected evacuation of cars exiting locations around the IRS building.

There would be many vehicles exiting the bombing locations requiring the fastest routes out, such as the ambulances. However, some emergency vehicles coming from the fire stations would require the fastest routes toward the bombing locations. For this particular study, three hospital locations and three fire station locations were identified as responders within the critical first hour. Although no hospitals are located within the simulated area, the routing solution was to use Google Maps to map the travel time to the point where the path to the hospital began in the coded network. The Google Maps travel time was then added to the simulation time to produce an estimate of the total travel time from the hospital to the disaster area.

\subsection{Disaster Scenario Assumptions}

One important assumption that was common to all disaster scenarios was that all the parking lots are filled to capacity due to the special events being organized (to make it essentially the worst-case scenario). In addition, some other assumptions common to all the scenarios included the HP Pavilion traffic leaving from the directly adjacent parking lot that would divide evenly onto Julian St., Cahill St., Almaden Blvd., and N. Autumn St. Also, for the San Jose Convention Center parking lot across from the convention center three fourths of the capacity would exit onto Almaden Blvd. from Woz Way. The other one fourth of vehicle traffic would exit onto Woz Way toward the Highway 87 NB off-ramp. The base case disaster scenario involved letting people evacuate as they might according to the assumptions stated above. This scenario is compared with the three different scenarios, which might affect the evacuation of downtown area. In each of the three cases the different travel times (for evacuees as well as for the emergency response personnel) are compared to this base case disaster scenario.

\subsection{Scenario 1}

The first contingency scenario was created to test the effect of an incident such as an accident or redevelopment resulting in road closure due to possible construction work. At the peak hour during the disaster scenario, one lane on Bird Ave was closed as cars were trying to leave the HP Pavilion and the other disaster areas. The closure was positioned 


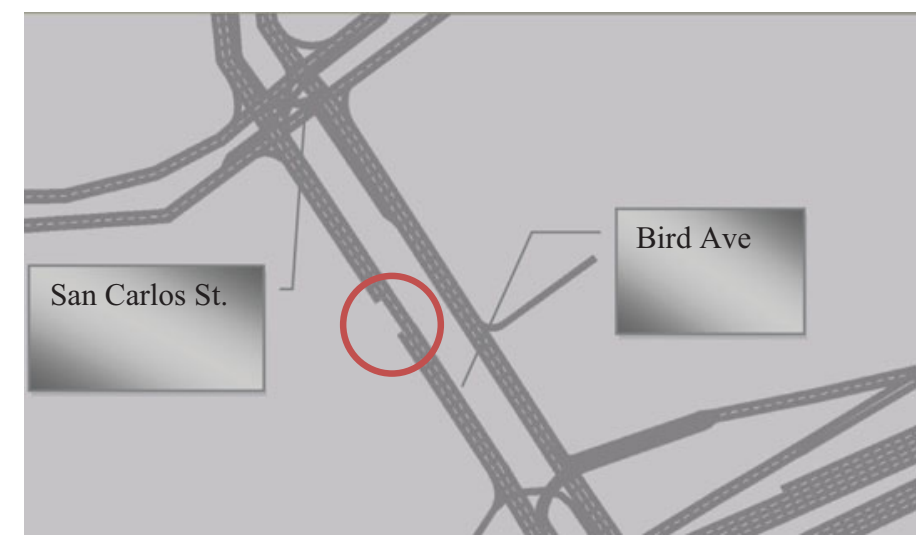

Figure 4. Scenario 1 link closure.

southbound along Bird Avenue between San Carlos St. and the I-280 NB onramp. Figure 4 depicts the location of the lane closure in Scenario 1.

\subsection{Scenario 2}

The second scenario was to test the effects, if any, of contraflow lanes exiting toward the freeway on S. Montgomery Street, beginning at the Montgomery and Park intersection, and heading southbound towards I-280 and past the on- and off-ramps. With all the traffic expected to depart from the HP Pavilion toward the freeway, the contraflow lanes were an attempt to provide another path to exit the area. Note that the contraflow is typically used in the situations with increased directional trip demand during hurricane evacuation. The scenario may not be the most effective in the current situation of no-notice evacuation. However, this scenario has been added herein to demonstrate the complex modeling process and the ability of the proposed approach to assess contraflow scenario. If contraflow has significant positive impact on evacuation, it should be considered as one of the strategies for evacuation and it would be worthwhile to devise a plan to include it even in the case of a no-notice disaster.

This was the most complex scenario to model because it involved traffic rerouting on at least four different streets and one freeway on-ramp. The expected congestion on Montgomery Street/Bird Avenue could potentially be alleviated by creating a path for left turning vehicles from San Carlos and Park Avenue to quickly exit toward I-280. Also, for vehicles heading east on both Park Avenue and San Carlos Street, right turning vehicles have two right turn lanes onto Montgomery Street/Bird Avenue. In addition, left turn and through movements from this intersection approach are prohibited.

Vehicles traveling west on San Carlos and Park Avenue will have one left-turn lane each when turning onto Montgomery Street/Bird Avenue. Through movements are prohibited, but from Park Avenue only emergency vehicles are allowed to make a right turn going NB toward the HP Pavilion. From San Carlos Street, right-turn movements are entirely prohibited for everyone including emergency vehicles because there is no emergencyvehicle-only lane.

Also, the Bird Avenue exits for both I-280 NB and SB are open to emergency assets only. In addition, for vehicles wanting access to the I-280 SB onramp to Bird Avenue, vehicles must be on the contraflow lanes, not the original lanes on Bird Avenue because 


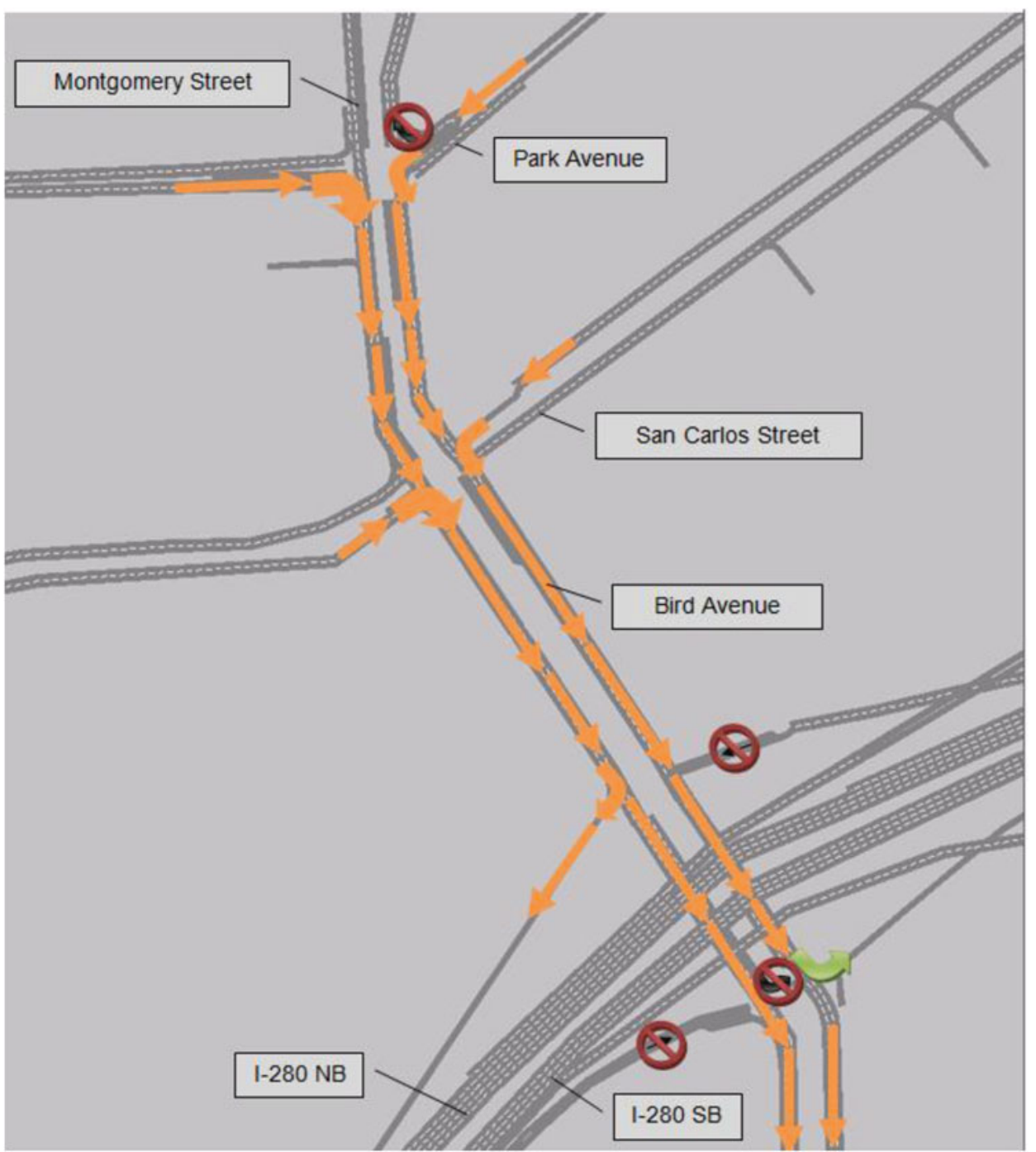

Figure 5. Scenario 2 contraflow lane scenario.

there will be no left turns from the original Bird Avenue lanes onto the I-280 SB ramp. The green arrow in Figure 5 indicates the permitted left turn movement from the contraflow lanes onto the freeway.

\subsection{Scenario 3}

The last scenario involved an assumption that if more people were to take public transit from Diridon Station to exit the disaster area, there could possibly be less congestion and a faster exit time from the disaster area for everyone. To implement this scenario, volume from the exiting parking lots of the disaster areas were reduced by $30 \%$ from their original volume. There were a total of 24 "parking lots" whose volumes were reduced as a result of the evacuees using the transit from the Diridon station. This scenario was created 
to demonstrate how effective public transit can be in a downtown area for contingency planning. It is worth mentioning that in VISSIM, any vehicle generating point within the simulation is called a "parking lot."

\subsection{Emergency Vehicle Routing}

VISSIM was applied to aid in determining the optimal routing strategy for dispatching a fleet of emergency response vehicles from fire stations while hospitals would see incoming patients from the various disaster areas. Based on the results from the simulation model for the traffic network in downtown San Jose, optimal routes for the three hospitals and three fire stations near the disaster areas were determined. The primary hospitals which would receive patients requiring medical attention were (1) O' Connor Hospital, (2) Valley Medical Center, and (3) Regional Hospital (HCA). The three fire stations that would certainly respond in a disaster scenario are all located in San Jose and are Fire Stations 1, 7 , and 30 .

For each scenario, including the base case, the fastest route was determined with the traffic simulation, along with Google Maps travel times. For example, from the HP Pavilion to O' Connor Hospital during the base case scenario, the fastest total time from beginning to end traveled via Montgomery, R onto Julian -> R onto Hwy $87 \mathrm{SB}$ onramp $->\mathrm{R}$ onto I- 280 NB -> R onto I- 880 NB -> Exit R onto Stevens Creek Blvd. -> L onto Bellerose -> L onto Forest. Because O'Connor Hospital was outside the simulated network a Google Maps time was substituted for the time until a coded network road began in the simulation. Therefore, while the total travel time was $11.3 \mathrm{~min}, 5$ min was the Google Maps travel time, and 6.3 min was the simulation time.

However, for the fire stations, two out of the three fire stations were contained within the network, and the travel times from the fire stations to each of the disaster areas were recorded. To record the travel time for the emergency vehicles, two new vehicle compositions were created. For network locations where emergency vehicles and other vehicles could emerge together, a vehicle composition called "Car + Emergency" was created that would generate $3 \%$ of the total flow as emergency vehicles. In situations where only fire station vehicles would emerge, a separate vehicle composition called "Fire stations" was created, and consisted of heavy gross vehicles (HGV) that would represent the fire trucks and engines. New routing decisions for the vehicles were created and directed to the disaster sites, as well.

\subsection{Disaster Areas to Hospital}

For the tested scenarios it was found that the travel times for ambulances from the disaster site to O'Connor Hospital were relatively consistent for all four scenarios. For example, an ambulance traveling from the HP Pavilion to O'Connor Hospital would encounter an identical travel time in Scenarios 1 to 3, including the base case scenario. Likewise, if ambulances were going from the San Jose Convention Center, the travel times would be relatively consistent and differed by a maximum of half of a minute. One of the reasons for the consistent travel times is that ambulances going to O'Connor Hospital were each traveling on the most optimized routes, which happen to be the same routes for each scenario.

For ambulances dispatched to Santa Clara Valley Medical Center from the HP Pavilion, the results were very similar in their consistency to that of O'Connor Hospital, except for the differing travel times. Overall, the emergency vehicle travel times from San Jose Convention 
Center accounted for the least amount of total time traveled. It can be concluded here that for trips to Santa Clara Valley Medical Center, the travel time is mostly unaffected by the existing traffic, as well as additional congestion created by the mass evacuation of vehicles from the disaster area parking lots. The reason for this is that most of the ambulance route from San Jose Convention Center is on Interstate 280 NB, which would encounter less of an impact compared to local and collector roads near the disaster area.

For ambulances from the HP Pavilion, none of the scenarios showed significant differences in travel time. This is due in large part to ambulances having sole access to Highway 87. It suggests that authorities may be able to get help to the HP Pavilion victims quite easily under the given circumstances. Without any congestion, the ambulances were able to quickly gain access to the necessary route from the HP Pavilion compared to other route options, which traveled less distance, but would have to travel on local roads.

Traveling from the IRS building would be the most time consuming route for the base case, Scenario 1, and Scenario 2. The results are an indication of the congestion severity encountered along Santa Clara Street that was seen during the simulation runs. For the base case, Scenario 1, and Scenario 2, the simulation showed that vehicles would travel quickly along Highway 87 but would encounter severe congestion approaching via the Santa Clara Street off-ramp. Other route options explored consumed even more time than the ultimate, fastest route according to the simulation. For ambulances traveling from 100 Paseo de San Antonio, there were no significant differences in travel time.

The results of the Regional Medical Center travel time comparison shows a very consistent travel time for ambulances going from HP Pavilion. This can be attributed again to emergency vehicles having exclusive access to Highway 87, thereby avoiding any congestion from the local roads. For ambulances traveling from the San Jose Convention Center, there was the same consistency in travel times compared to ambulances traveling from the HP Pavilion. Ambulance access from the State Building would take the longest amount of time for any of the scenarios due to the congestion on 4th Street attempting to access I-280 NB. For ambulances heading from the State of California building at 100 Paseo de San Antonio, the travel times were relatively consistent.

\subsection{Fire Station Dispatch to Disaster Areas}

Travel times from fire stations to disaster areas are show in Table 2. For fire stations dispatching emergency vehicles to HP Pavilion, Fire Station 7 was the fastest primary responder in all four of the simulated scenarios. In addition, for the IRS building, because Fire Station 1 was only 0.2 miles away from the IRS building, it should definitely be the dispatch fire station with a total travel time of fewer than $2 \mathrm{~min}$ for all the scenarios. Lastly, for the State of California building, Fire Station 1 offered the shortest travel time for all the scenarios. The travel times ranged from approximately 2 to 3 min from Fire Station 1. Note that these travel times may be measured for any set of origin-destination locations in VISSIM. Hence, the model will allow authorities to assess alternative sites as potential dispatch locations while planning for such disasters.

\subsection{Scenario Comparisons for the Evacuees}

Although the specific destination is not listed in Table 3, it does generally show the improving or worsening travel times for each scenario from the disaster locations. The worsened travel time from the HP Pavilion for Scenario 1 is caused by the simulated incident that closed a lane of traffic towards the I-280 SB and NB ramps. The incident 
Table 2

Fastest times to disaster areas from fire stations

\begin{tabular}{|c|c|c|c|c|c|}
\hline Fire Station & Destination & $\begin{array}{c}\text { Total Time } \\
\text { Base Case } \\
\text { (minutes) }\end{array}$ & $\begin{array}{l}\text { Total Time } \\
\text { Scenario 1: } \\
\text { Lane Closure } \\
\text { (minutes) }\end{array}$ & $\begin{array}{l}\text { Total Time } \\
\text { Scenario 2: } \\
\text { Contraflow } \\
\text { (minutes) }\end{array}$ & $\begin{array}{c}\text { Total Time } \\
\text { Scenario 3: } \\
\text { Public Transit } \\
\text { (minutes) }\end{array}$ \\
\hline \multirow{4}{*}{$\begin{array}{r}\text { Fire station } 1 \\
(225 \text { North } \\
\text { Market St.) }\end{array}$} & HP Pavilion & 9.7 & 9.6 & 9.7 & 9.5 \\
\hline & $\begin{array}{l}\text { San Jose } \\
\text { Convention } \\
\text { Center }\end{array}$ & 8.2 & 8.5 & 7.6 & 8.2 \\
\hline & IRS building & 3.4 & 3.9 & 3.6 & 3.5 \\
\hline & $\begin{array}{l}\text { State of } \\
\text { California } \\
\text { Building }\end{array}$ & 2.5 & 2.5 & 2.3 & 2.3 \\
\hline \multirow{4}{*}{$\begin{array}{l}\text { Fire station } 7 \\
\text { (800 Emory } \\
\text { St.) }\end{array}$} & HP Pavilion & 3.5 & 3.5 & 3.5 & 3.5 \\
\hline & $\begin{array}{l}\text { San Jose } \\
\text { Convention } \\
\text { Center }\end{array}$ & 6.3 & 7.8 & 7.2 & 7.4 \\
\hline & IRS building & 8.0 & 8.4 & 8.3 & 8.4 \\
\hline & $\begin{array}{l}\text { State of } \\
\text { California } \\
\text { Building }\end{array}$ & 9.0 & 10.3 & 10.2 & 10.3 \\
\hline \multirow{4}{*}{$\begin{array}{l}\text { Fire station } 30 \\
\text { (454 Auzerais } \\
\text { Ave.) }\end{array}$} & HP Pavilion & 2.9 & 2.9 & 4.0 & 2.5 \\
\hline & $\begin{array}{l}\text { San Jose } \\
\text { Convention } \\
\text { Center }\end{array}$ & 1.9 & 1.8 & 1.2 & 1.4 \\
\hline & IRS building & 7.1 & 6.1 & 5.6 & 3.0 \\
\hline & $\begin{array}{l}\text { State of } \\
\text { California } \\
\text { Building }\end{array}$ & 7.0 & 2.9 & 2.3 & 2.0 \\
\hline
\end{tabular}

directly influenced vehicles' travel time leaving the HP Pavilion. It indicates that for evacuating the HP Pavilion, the contraflow strategy in Scenario 2 is the best option because it reduced the evacuation time by half compared to the base case. Also, note that Scenario 2 contained contraflow lanes designed specifically to alleviate the congestion anticipated from vehicles exiting from the HP Pavilion. However, the contraflow lanes were not able to reduce the travel time from the HP Pavilion to the vehicles' intended destinations better than Scenario 3, when vehicular traffic from the disaster parking lots was reduced by $30 \%$. An unintended consequence of the contraflow lanes was the rerouting of vehicles onto adjacent streets, which directly affected the evacuees' travel time from the San Jose Convention 
Table 3

Travel time for evacuees

\begin{tabular}{|c|c|c|c|c|}
\hline \multirow[b]{2}{*}{ Origin } & \multicolumn{4}{|c|}{ Travel Time (minutes) } \\
\hline & Base Case & $\begin{array}{c}\text { Scenario } 1 \\
\text { (Lane Closure) }\end{array}$ & $\begin{array}{c}\text { Scenario } 2 \\
\text { (Contraflow) }\end{array}$ & $\begin{array}{c}\text { Scenario } 3 \\
\text { (Public Transit) }\end{array}$ \\
\hline HP Pavilion & 11.5 & 15.6 & 5.9 & 8.5 \\
\hline San Jose Convention Center & 5.6 & 5.0 & 6.0 & 4.1 \\
\hline IRS building & 9.9 & 9.8 & 9.7 & 8.4 \\
\hline State of California Building & 7.1 & 7.1 & 5.6 & 5.3 \\
\hline
\end{tabular}

Center. However, because the increase in travel time is from 5 minutes to 6 minutes, it may be an acceptable trade-off. It is worth noting that Scenario 3 (with $30 \%$ fewer trips due to transit support) produced the fastest travel times from all the disaster areas save Scenario 2's HP Pavilion trips, which featured contraflow lanes to aid in the general public's departing of the area.

\section{Conclusions}

The primary goal for this research was to apply the simulation modeling approach to investigate the various evacuation strategies and scenarios for a human-caused disaster in downtown San Jose. To accomplish this goal, first a microscopic simulation model to evaluate the pre- and postdisaster performance of the downtown street network was developed in VISSIM. Google Maps and the manual observation of the network were used to code the network correctly in terms of the lane-configuration, traffic signals, and related factors. The network was coded to have evening peak hour volumes in order to account for the worst case scenario in terms of traffic.

The simulation model created in this study was used to identify efficient routing strategies for four different scenarios. The four scenarios were chosen based on the different complications or potential improvements that could be made in the event of a large-scale terrorist attack on San Jose. The fastest route for each of the four scenarios was chosen after averaging the travel times from the 10 simulation runs. These fastest routes were identified not only for the evacuees to exit the downtown, but also for fire dispatch vehicles and ambulances to reach the targeted locations from nearby fire stations and hospitals.

Under the "do-nothing" base disaster scenario the most severe traffic bottlenecks occurred along Santa Clara Street and Montgomery Street, as many vehicles exiting from the surrounding HP Pavilion parking lots attempted to flee the area. The Santa Clara Street bottleneck began at the intersection of Santa Clara Street and Cahill Street and continued until Santa Clara Street and Market Street. As for the Montgomery Street bottleneck, the worst traffic occurred from the intersection of Montgomery Street and Santa Clara to Montgomery Street and the I-280 on and off-ramps. This information from the base case disaster scenario can be used by emergency response planners to come up with different scenario that can improve traffic. In this research the value of the simulation model was demonstrated by four different scenarios (summarized above).

Contraflow lanes on Montgomery Street/Bird Avenue helped to reduce the bottleneck on Montgomery Street and subsequently reduced the bottleneck on Santa Clara Street as well, with fewer cars able to turn onto Santa Clara Street from Autumn Street. Therefore, 
any bottleneck directly associated by implementing contraflow can be alleviated by the fact that the reversal begins at the intersection of Park Avenue and Montgomery Street. In addition to providing two contraflow lanes for the general public to exit the disaster area, one of the lanes immediately adjacent to the contraflow lanes was used only for emergency vehicle access to HP Pavilion. This was used in Scenario 2, but did not seem to produce a more efficient travel time compared to scenarios without the emergency-vehicle-only lane on Montgomery Street.

As expected, reducing the number of evacuating vehicles on the road is the best scenario in terms of reduced travel times. In the scenario where $30 \%$ of traffic was diverted to transit via the Diridon Transit Center, the least amount of congestion was encountered by the remaining evacuees, as well as emergency responders. Although this is a logical conclusion, putting it into practice and implementing a plan of having drivers abandon their vehicles in a car-oriented society would be a challenge and needs advanced planning and preparation. Also, note that we have chosen the $30 \%$ model shift for illustration purposes here. Estimating the actual percentage for this would require investigation evacuee behavior and attitudes about abandoning the personal vehicles which is beyond the scope of this research. Regardless, it is clear that the higher this percentage the smoother the emergency response operation would proceed. It would help to have sufficient communication from emergency responders and emergency planning to advertise their plan in a way to effectively communicate this idea. The authorities also need to be mindful of the possibility that an attack might put the transit lines at risk. In the absence of transit (possibly due to potential attacks on station or on tracks), the contraflow lanes (Scenario 2) will be helpful. It is worth noting that it is possible for emergency professionals to devise even more effective scenarios that can be evaluated using the simulation model developed in this research. As mentioned above, though the real value of this research is not necessarily in identifying the best possible strategy but demonstrating how any evacuation and response strategy can be evaluated using the simulation model developed in this research effort. It enables modeling of additional scenarios with marginal effort.

The simulation model developed herein can be used by emergency planners to keep revising the strategies and different evacuation scenarios to test what evacuation strategy works best for any given disaster scenarios. The revisions that can be assessed with the model include signal timing coordination, additional contraflow lanes, and impact of reserving other routes for emergency personnel use. If the evacuation planners would like to analyze more scenarios, it can be done at very little additional effort for downtown San Jose now that this model is available. The results of this research can also serve as a basis for further research into disaster planning. Time horizon of the evacuation, as well as the inclusion of more area, would be helpful. In this study many attempts were made to create a network that would be encompassed by Highway 101, I-880, and I-280 by creating detailed VISSIM network with all roads coded. However, the traffic assignments were never able to converge with so many details and large amount of traffic. Based on investigators' experience, increasing the modeled area might make it impossible to model the network in the detail attained here. Mesoscopic modeling (instead of very detailed microscopic approach used here), such as the cell transmission model, may be used in that case. From the queue clearance observation during the VISSIM simulation, even after background traffic had mostly diminished, queues would take some time to clear the network. Therefore, a potential investigation would delve deeper into the data to estimate a point in time where queues have successfully cleared the network from an emergency management standpoint.

Simulated downtown San Jose network may be used for many other applications as well. In addition to evacuation applications, one can examine the quality of traffic flow 
in downtown San Jose through an application such as the two-fluid model. Any proposed changes to the network, such as lane-widening or one-way streets, could be easily coded into the existing VISSIM model, and the resulting quality of traffic flow can be represented with new two-fluid model parameters. It could help assess the impact of the newly proposed improvement on the traffic flow. Given the accuracy of the model, it is a valuable tool for the City of San Jose to assess the impact of operational changes on the entirenetwork.

\section{References}

Boxill, S. A., \& Yu, L. (2000). An evaluation of traffic simulation models for supporting ITS development (SWUTC/00/167602-1). College Station, TX: Southwest Region University Transportation Center.

Dixit, V. V., Ramasamy, S., \& Radwan, E. (2008). Assessment of I-4 contraflow plans: microscopic versus mesoscopic simulation. Transportation Research Record: Journal of the Transportation Research Board, 2041, 89-97.

Dowling, R., Skabardonis, A., \& Alexiadis, V. (2004). Traffic analysis toolbox volume III: Guidelines for applying traffic microsimulation modeling software FHWA-HRT-04-040. Washington, DC: Federal Highway Administration.

Elmitiny, N., Ramasamy, S., \& Radwan, E. (2007). Emergency evacuation planning and preparedness of transit facilities: Simulation modeling. Transportation Research Board: Journal of the Transportation Research Board, 1992, 121-126.

Federal Highway Administration. (2012) Retrieved from http://ops.fhwa.dot.gov/ trafficanalysistools/tat_vol3/sect5.htm

Haghani, A., Hu, H., \& Tian, Q. (2003). An optimization model for real-time emergency vehicle dispatching and routing. Transportation Research Board Annual Meeting CD-ROM. Retrieved from http://www.ltrc.lsu.edu/TRB_82/TRB2003-000710.pdf

Mollaghasemi, M., \& Abdel-Aty, M. (2003). Post-Disaster Dynamic Routing of Emergency Vehicles: Development of emergency response model for Orlando International Airport (No. BC096/RPWO\#17). Tallahassee, FL: Florida Department of Transportation. Retrieved from http://www.dot.state.fl.us/research-center/Completed_Proj/Summary_ TE/FDOT_BC096_17_rpt.pdf

Naghawi, H., \& Wolshon, B. (2010). Transit-based emergency evacuation simulation modeling. Journal of Transportation Safety \& Security, 2(2), 184-201.

Pal, A., Graettinger, A. J., \& Triche, M. H. (2002, August). Emergency evacuation modeling based on Geographical Information System data. Retrieved from http://www.ltrc.lsu. edu/TRB_82/TRB2003-001689.pdf

Pande, A., Edwards, F., \& Yu, J. (2012). A framework for developing and integrating effective routing strategies within the emergency management decision-support system (CA-MTI-12-2901). San Jose, CA: San Jose State University, Mineta Transportation Institute.

Rousseau, G., Scherr, W., Yuan, F., \& Xiong, C. (2007). Linking Atlanta's regional transportation model with microscopic traffic simulation. Retrieved from http://www.ptvamerica.com/ fileadmin/files_ptvamerica.com/2007_NARSC_Rousseau_Scherr_et_al_Regional_Model_and MicroSim.pdf (accessed 2 September 2011)

Sisiopiku, V. P., Jones, S. L. Jr., Sullivan, A. J., Patharka, S. S., \& Tang, X. (2004). Regional traffic simulation for emergency preparedness (UCTA Report 03226). Tuscaloosa, AL: University Transportation Center for Alabama. Retrieved from http://utca.eng.ua.edu/files/2011/08/ 03226fnl.pdf.

Tagliaferri, A. (2005). Use and comparison of traffic simulation models in the analysis of emergency evacuation conditions (Master's thesis), North Carolina State University.

Theodoulou, G. (2003). Contraflow evacuation on the westbound contraflow evacuation on the westbound I-10 out of the City of New Orleans (Master's thesis), Louisiana State University. 